\title{
THE ELEVATED TEMPERATURE DEFORMATION OF G115 STEEL AND THE ASSOCIATED DEFORMATION MECHANISM
}

\author{
Sultan Alsagabi, Mohammed Alqahtani and Abdulaziz Alajlan \\ King Abdulaziz City for Science and Technology, \\ P.O. Box 6086, Riyadh 11442, Saudi Arabia
}

\begin{abstract}
The next Generation-IV reactors need to be stand for a very high temperature. Structural materials have to resist that temperature; otherwise, damages could appear. G115 steel is a candidate structural material which has been considered in this work. The hot deformation behavior of G115 steel was carried out at elevated temperatures 500, 550 and $600^{\circ} \mathrm{C}$ with different strain rates ranging from 1x10-5 to 1x10-3 s-1. To derive the hot deformation constitutive equation, the universal hyperbolic-sine Arrhenius-type equation was utilized considering the ultimate stresses values for each condition. As a result, the activation energy of G115, which will assess the high-temperature deformation mechanism, was obtained to be $331 \mathrm{KJ} / \mathrm{mol}$.
\end{abstract}

\section{KEYWORDS}

G115, New generation nuclear reactor, Deformation., Advanced Materials

\section{INTRODUCTION}

The energy demand in the recent years is growing fast. Therefore, it is important to reduce the greenhouse emissions [1-3]. Because of that, nuclear energy is becoming a crucial candidate for non-released gas. Nowadays, Generation-II and Generation-III are the most of the operating commercial nuclear reactors where initially many reactor types were considered. However, and taking into account the most promising technologies, certain types of reactors were considered to meet the goals of the Generation-IV initiative. Up to date, Generation-IV reactors are a set of mostly theoretical nuclear reactor designs. The inside temperature of the Generation-IV reactors are to be designed based on about $750^{\circ} \mathrm{C}$. Many researches have been applied in the last decades to test the mechanical properties of those metals that are exposed to high temperature.

At high temperature (close to the assumed Generation-IV reactor temperature), the recrystallization and plastic deformation of metallic materials occur, where the recrystallization temperature is about as $1 / 3$ to $1 / 2$ of the melting temperature [2-3]. Deformation of steel at high temperatures involves work hardening, recovery and recrystallization process.

The nominal composition of G115 steel is 9Cr-3W-3Co (in wt. \%) which has a very good properties. For example, low thermal expansion coefficient, high creep and tensile strength, toughness and high thermal conductivity. These features are required in a high temperature operation. Different steel alloys were investigated to address the elevated temperature 
deformation mechanism which occurs to be much higher than that of iron self-diffusion [4-8]. To illustrate, different microstructural evolution mechanisms occurs at elevated temperature under loading which alter mechanical characteristics [9-13]. However, more work was devoted to address the creep properties and the related microstructural stability [4-8].

The present work is to investigate the effect of normalizing temperature of $9 \mathrm{Cr}-3 \mathrm{~W}-3 \mathrm{Co}$ steel where in the last few years attentions have been paid on G115. This new sort of steel with excellent properties is expected to be used in Generation-IV reactor type for up to $750^{\circ} \mathrm{C}$. As Generation-IV reactor has already been designed to work at a very high temperature (550 to $700^{\circ} \mathrm{C}$ ), many investigations have been studying to find the most candidate material that can be afforded under a high temperature circumstances. Thus, the intention of this work is to investigate the mechanical characteristics and the elevated temperature deformation mechanism of G115 which is a candidate structural material of the Next Generation Nuclear Plants, NGNP.

\section{EXPERIMENTAL PROCEDURE}

The investigated material, G115, was procured from Bao-Shan Iron and steel Company (BaoSteel). The Central Iron and Steel Research Institute CISRI of china has developed G115 ferritic heat resistant steel which has the chemical composition as shown in Table 1.

Table 1: Main chemical composition of G115 steel (wt\%).

\begin{tabular}{|c|c|c|c|c|c|c|c|c|}
\hline $\mathrm{C}$ & $\mathrm{Cr}$ & $\mathrm{W}$ & $\mathrm{Co}$ & $\mathrm{V}$ & $\mathrm{Nb}$ & $\mathrm{N}$ & $\mathrm{B}$ & $\mathrm{Fe}$ \\
\hline 0.076 & 8.83 & 3.11 & 2.99 & 0.19 & 0.042 & 0.014 & 0.013 & Bal. \\
\hline
\end{tabular}

The tensile testing was performed at different elevated temperatures using an Instron universal tester, where each temperature was remain within $\pm 5^{\circ} \mathrm{C}$ for an hour. Samples for each test were machined with a gage diameter and length of $6.4 \mathrm{~mm}$ and $25.4 \mathrm{~mm}$, respectively, to perform tensile testing at different strain rates and elevated temperatures. To illustrate, tensile testing were conducted at temperatures of 500,550 and $600^{\circ} \mathrm{C}$ and different strain rates from $1 \times 10^{-5}$ to $1 \times 10^{-3}$ $\mathrm{s}^{-1}$. After that, the universal hyperbolic-sine Arrhenius-type equation was utilized to derive the hot deformation constitutive equation for the tested metal at any temperature, flow stress and strain rate.

\section{RESULTS AND DISCUSSION}

\subsection{Flow behavior at elevated temperature}

The true stress-strain behavior at different temperature 500,550 and $600^{\circ} \mathrm{C}$ and different strain rates are illustrated in Table 2. According to Table 2, the strength of the tested material (G115) showed a slight decrease in strength as the temperature rise. Similarly, as strain rate decreases the strength is also decreases. The highest strength was obtained at the lowest temperature along highest strain rate (i.e. $500^{\circ} \mathrm{C}$ and $1 \times 10-3 \mathrm{~s}^{-1}$ ). 
International Journal of Advances in Materials Science and Engineering (IJAMSE) Vol.7, No.1, January 2018

Table 2: Obtained stresses values at different temperatures and strain rates.

\begin{tabular}{|c|c|c|c|c|c|c|}
\hline Temperature & \multicolumn{2}{|c|}{$500{ }^{\circ} \mathrm{C}$} & \multicolumn{2}{c|}{$550{ }^{\circ} \mathrm{C}$} & \multicolumn{2}{c|}{$600{ }^{\circ} \mathrm{C}$} \\
\hline Strain Rate $^{-1}$ & $\sigma_{\mathrm{u}}[\mathrm{MPa}]$ & $\sigma_{\mathrm{y}}[\mathrm{MPa}]$ & $\sigma_{\mathrm{u}}[\mathrm{MPa}]$ & $\sigma_{\mathrm{y}}[\mathrm{MPa}]$ & $\sigma_{\mathrm{u}}[\mathrm{MPa}]$ & $\sigma_{\mathrm{y}}[\mathrm{MPa}]$ \\
\hline $1.00 \times 10^{-3}$ & 1050 & 830 & 902 & 727 & 793 & 651 \\
\hline $5.00 \times 10^{-4}$ & 941 & 805 & 862 & 691 & 729 & 602 \\
\hline $1.00 \times 10^{-4}$ & 912 & 791 & 794 & 653 & 690 & 588 \\
\hline $5.00 \times 10^{-5}$ & 881 & 751 & 709 & 591 & 637 & 543 \\
\hline $1.00 \times 10^{-5}$ & 805 & 669 & 687 & 577 & 594 & 501 \\
\hline
\end{tabular}

\subsection{Constitutive equation for high temperature flow stress}

At high temperatures, the relation between deformation-temperature, flow stress and strain rate can be expressed by the universal hyperbolic-sine Arrhenius-type equation which expressed in Eq. 1[3-5].

$$
\dot{\varepsilon}=A[\sinh (\alpha \sigma)]^{n} \exp \left(-\frac{Q}{R T}\right)
$$

Where $\varepsilon^{\prime}$ is stain rate $\left(\mathrm{s}^{-1}\right)$,

$\mathrm{A}, \alpha$ and $\mathrm{n}$ are constants,

$\sigma$ is flow stress $(\mathrm{MPa})$,

$\mathrm{Q}$ is activation energy $(\mathrm{KJ} / \mathrm{mol})$,

$\mathrm{R}$ is the universal gas constant $\left(8.31 \mathrm{~J} \mathrm{~mol}^{-1} \mathrm{~K}^{-1}\right)$,

And $\mathrm{T}$ is absolute temperature $(\mathrm{K})$.

To determine the material constants for the constitutive equation, the natural logarithm on both sides of Eq. 1 can be applied and the peak stress $\sigma_{\mathrm{u}}$ in Eq. 1 can be used to have better description for the hot deformation [4-5] that will be expressed as:

$$
\ln \left[\sinh \left(\alpha \sigma_{u}\right)\right]=\frac{\ln \varepsilon}{n}+\frac{Q}{n R T}-\frac{\ln A}{n}
$$

For the purpose of writing the equation of the investigated steel, the parameters beginning with $\alpha$ that was defined as [1, 3-5]:

$$
\alpha=\frac{\beta}{n^{\prime}}
$$

Where the values of $\beta$ and n' can be found using the main Zener-Holloman parameter in an exponent type equation which yields [1-3]:

$$
\begin{aligned}
& \dot{\varepsilon}=B \sigma^{n} \\
& \dot{\varepsilon}=C \exp (\beta \sigma)
\end{aligned}
$$

Where, $B$ and $C$ are constants of the material.

By taking natural logarithm on both sides in Eq. 4 and Eq. 5: 
International Journal of Advances in Materials Science and Engineering (IJAMSE) Vol.7, No.1, January 2018

$$
\begin{aligned}
& \ln \sigma=\frac{1}{n} \ln \varepsilon-\frac{1}{n} \ln B \\
& \sigma=\frac{1}{\beta} \ln \varepsilon-\frac{1}{\beta} \ln C
\end{aligned}
$$

Then, the partial derivative for Eq. 6 and Eq. 7 for constant temperature yields:

$$
\begin{aligned}
& \beta=\left[\frac{\partial \ln \dot{\varepsilon}}{\partial \sigma}\right]_{T} \\
& n^{\prime}=\left[\frac{\partial \ln \varepsilon}{\partial \ln \sigma}\right]_{T}
\end{aligned}
$$

Then, the linear regression of data points in Table 2 can be utilized to plot lné versus $\sigma$ to find $\beta$ as it shown in Fig. 1 and to plot lnć versus ln $\sigma$ to find n' as in Fig. 2.

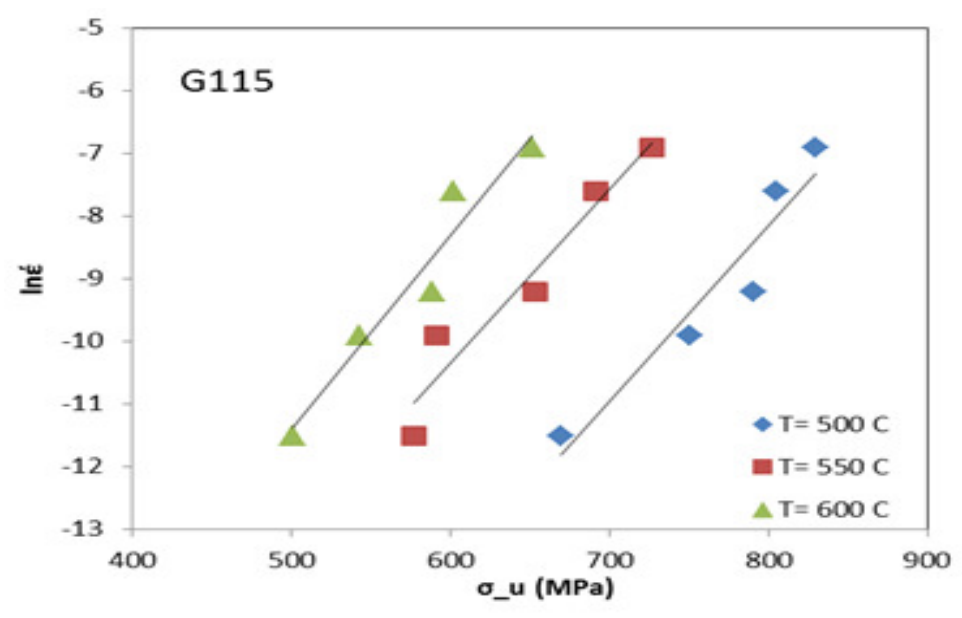

Figure $1:$ the plot of lné versus $\sigma$

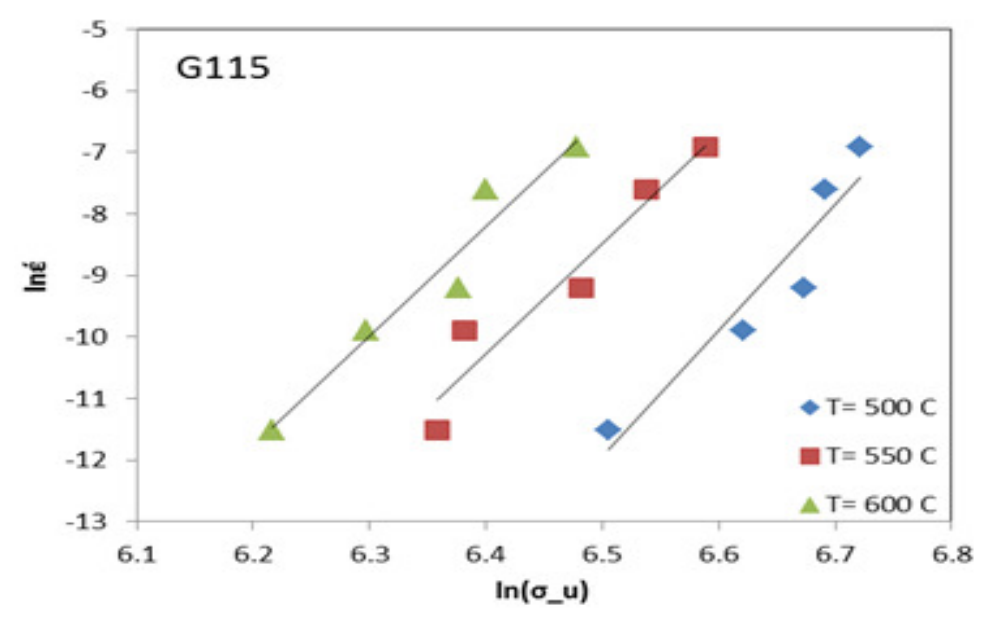

Figure 2 : the plot lné versus $\ln \sigma$ 
International Journal of Advances in Materials Science and Engineering (IJAMSE) Vol.7, No.1, January 2018

From Fig. 1 we can find that $\beta=0.0289$, and Fig. 2 we found $n '=18.76$. Using these values and Eq. 3 we find $\alpha$ to be 0.00154 .

Then we take the partial derivative for Eq. 1 two times; one with constant temperature and the other with constant strain rate, which will lead to:

$$
\begin{array}{r}
\frac{1}{n}=\left[\frac{\partial \ln \sinh (\alpha \sigma)}{\partial \ln \varepsilon}\right]_{T} \\
Q=n R\left[\frac{\partial \ln \sinh (\alpha \sigma)}{\partial \ln \frac{1}{T}}\right]_{\dot{\varepsilon}}
\end{array}
$$

Then, we can use the linear regression of data points of the plot $\ln (\sinh (\alpha \sigma))$ versus $\ln \varepsilon$ to find $n$ in Fig. 3 and the linear regression of data points of the plot $\ln (\sinh (\alpha \sigma))$ versus $1000 / T$ to find Q as in Fig. 4 (note here we use 1000/T rather that 1/T to have Q in $\mathrm{KJ} / \mathrm{mol}$ ).

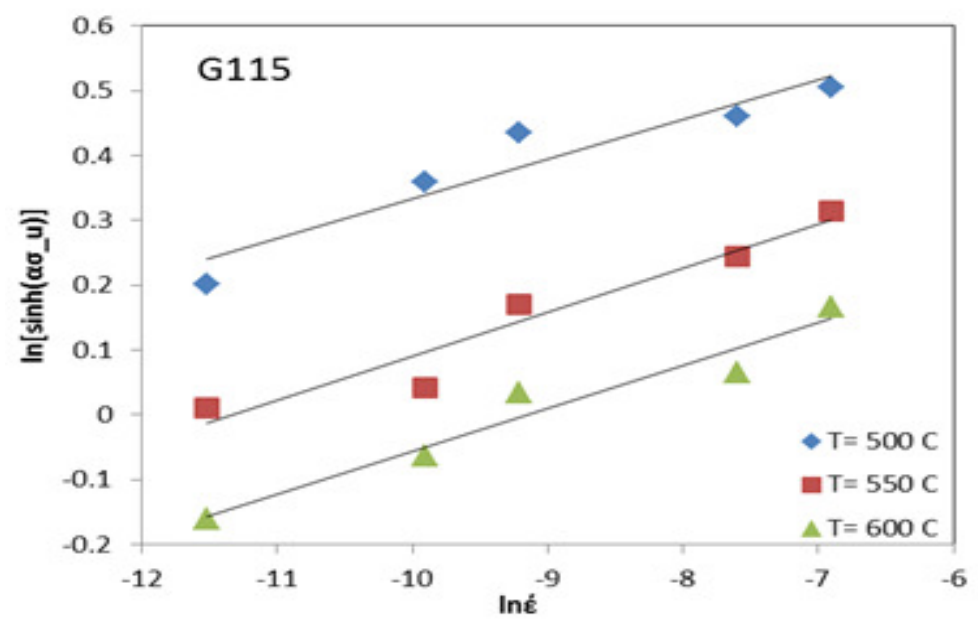

Figure 3 : the plot $\ln \sinh (\alpha \sigma)$ versus lné

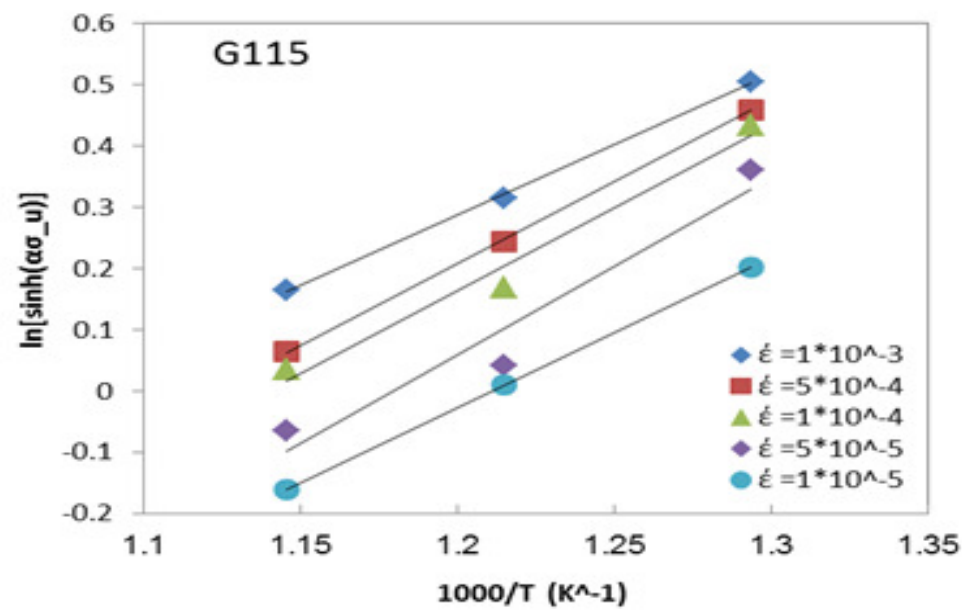

Figure 4: the plot $\ln \sinh (\alpha \sigma)$ versus $1000 / \mathrm{T}$ 
International Journal of Advances in Materials Science and Engineering (IJAMSE) Vol.7, No.1, January 2018

From Fig. $3 \mathrm{n}$ was estimated to be 15.31 and from Fig. $4 \mathrm{Q}$ was obtained as $331.25 \mathrm{KJ} / \mathrm{mol}$, which comes in good agreement with different ferritic steel data for steel alloys [16].

Using Eq. 1 or Eq. 2 to substitute the values of T, $\varepsilon, \alpha, n, \sigma$ and $\mathrm{Q}$ for one data points to find $\mathrm{A}=$ $1.102 \mathrm{E}+16$.

Finally, it has been derived that the hot deformation constitutive equation for the tested metal at any temperature, flow stress and strain rate can be written as:

$$
\dot{\varepsilon}=1.202^{16}[\sinh (0.00154 \sigma)]^{15.31} \exp \left(-\frac{331250}{R T}\right)
$$

\section{CONCLUSION}

- The elevated temperature deformation behavior was conducted for the investigated steel along different strain rates.

- The elevated temperature strength decreases as temperature increases or strain rate decreases where maximum ultimate stress was obtained at $500^{\circ} \mathrm{C}$ and $1 \times 10^{-3} \mathrm{~s}^{-1}$.

- The activation energy of G115 steel was obtained to be $331 \mathrm{KJ} / \mathrm{mol}$, which indicates that relevant hot deformation equation of G115 within the testing temperatures and strain rates.

\section{REFERENCES}

[1] S. Mandal, S V. Rakesh, P.V. Sivaprasad, S. Venugopal \& K.V. Kasiviswanathan, (2009) "Constitutive equations to predict high temperature flow stress in a Ti-modified austenitic stainless steel”, Mater. Sci. Eng. A, Vol 500, pp114-121.

[2] W. D. Callister,D. G. Rithwisch, Material Science and Engineering, sixth ed., John Wiley \& Sons, Inc., New York, 2003.

[3] Information on http://www.chevron.com/globalissues/energysupplydemand/.

[4] F. Abe, (2011) "Strengthening mechanisms in creep of advanced ferritic power plants steels based on creep deformation analysis" Advanced Steels, Vol (A2011), pp409-422.

[5] V. Dudko, A. Belyakov and R. Kaibyshev, (2012) "Effect of tempering on mechanical properties and microstructure of a 9\% Cr heat resistant steel”, Mater. Sci. Forum, Vol 706, pp841-846.

[6] V. Sklenicka, K. Kucharova, M. Svoboda, L. Kloc, J. Bursik and A. Kroupa, (2003) "Long-term creep behavior of 9-12\%Cr power plant steels", Mater. Charact., Vol 51, pp35-48.

[7] J.S. Lee, H.G. Armaki, K. Maruyama, T. Muraki and H. Asahi, (2006) "Causes of breakdown of creep strength in $9 \mathrm{Cr}-1.8 \mathrm{~W}-0.5 \mathrm{Mo}-\mathrm{VNb}$ steel”, Mater. Sci. Eng. A, Vol 428, pp270-275.

[8] R. Shi and Z. Liu, (2011) "Hot Deformation Behavior of P92 Steel Used for Ultra-Super-Critical Power Plants”, J. Iron Steel Res. Int., Vol 18, pp53-58. 
International Journal of Advances in Materials Science and Engineering (IJAMSE) Vol.7, No.1, January 2018

[9] L. Wang, M. Li and J. Almer, (2013) "In-situ characterization of grade 92 steel during tensile deformation using concurrent high energy X-ray diffraction and small angle X-ray scattering”, J. Nucl. Mater., Vol 440, pp81-90.

[10] M. Yoshizawa, M. Igarashi, K. Moriguchi, A. Iseda, H.G. Armaki and K. Maruyama, (2009) "effect of precipitates on long-term creep deformation properties of P92 and P122 type advanced ferritic steels for USC power plants”, Mater. Sci. Eng. A, Vol 510, pp162-168.

[11] J. Hald, (2008) "microstructure and long-term creep properties of 9-12\% Cr steels" Int. J. Pressure Vessels Piping, Vol 85, pp30-37.

[12] F. Abe, T. Horiuchi, M. Taneike and K. Sawada, (2004) "stabilization of martensitic microstructure in advanced 9cr steel during creep at high temperature”, Mater. Sci. Eng. A, Vol 378, pp299-303.

[13] J. Zhao, D.M. Li and Y.Y. Fang, (2010) "application of manson-haferd and larson-miller methods in creep rupture property evaluation of heat-resistant steels", J. Pressure Vessel Technol., Vol 132, pp064502-064506.

[14] Z.J. Pu, K.H. Wu, J. Shi \& D. Zou, (1995) “development of constitutive relationships for the hot deformation of boron microalloying TiAl-Cr-V alloys", Mater. Sci. Eng. A, Vol. 192-193, pp780787.

[15] Y.C. Lin, M. Chen \& J. Zhong, (2008) "Constitutive modeling for elevated temperature flow behavior of 42CrMo steel”, Comp. Mater. Sci., Vol. 42, pp470-477.

[16] T. Shrestha, M. Basirat, I. Charit ,GP Potirniche, KK Rink, U Sahaym. (2012) "Creep deformation mechanisms in modified 9Cr-1Mo steel" J. Nucl. Mater., Vol 423, pp110-119.

\section{AUTHORS}

Sultan Alsagabi: National Center for Nuclear Technology (NCNT) employee at King Abdulaziz City for Science and Technology (researcher)

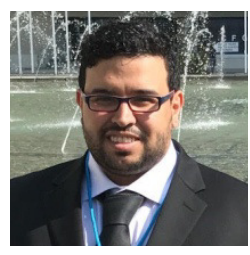

Mohammed Alqahtani and Abdulaziz Alajlan (National Center for Nuclear Technology (NCNT) employees at King Abdulaziz City for Science and Technology -researchers) 